\title{
Strategi Komunikasi Marketing Public Relations Barli Coffee
}

\author{
Agung Priyono*, Dadi Ahmadi \\ Prodi Public Relation, Fakultas Ilmu Komunikasi, Universitas Islam \\ Bandung, Indonesia.
}

*Priyonoagung39@gmail.com, dadi.ahmadi@gmail.com

\begin{abstract}
Barli Coffee, one of the Coffee Shops in the city of Bandung, which is adjacent to the Art Museum, has a different concept from other Coffee Shop concepts. Entering the era of globalization, competition in various fields is getting real. The success of the performance of Public Relations as an important item of the organization or company tasked with creating and maintaining a positive value or image of the organization is getting higher. When viewed from the marketing mix carried out by Barli Coffee, there are several marketing mixes that are applied to the marketing strategy process at Barli Coffee, namely the initial marketing strategy, which was carried out in the first month by Barli, namely doing live music. The second marketing strategy, which Barli Coffee Shop does is to carry the concept of "Friday I'm In Love" this concept intends to hold a promo every Friday. The "Friday I'm In Love" promo was established since the PSBB was tightened and the concept of the promo is that every consumer who comes can pay sincerely. The third marketing strategy carried out by activities that can be carried out at Barli Coffee is such as podcasts and live concerts. The researcher wanted to find out more about Barli Coffee's marketing public relations communication strategy regarding the promotion of "Friday I'm In Love". The aim is to find out the process of marketing public relations communication strategy, the obstacles that occur during the marketing public relations communication strategy process, and the reasons why choosing social media as a promotional medium. The research methodology is a qualitative-descriptive method with a single holistic case study research approach. Data collection techniques are carried out by interview, observation, documentation, and literature study. The research subjects of key informants consist of internal parts sales \& marketing, and barista Barli Coffee and supporting informants, owner of Barli Coffee. The result of the research is that the pull strategy applies tactics to promote "Friday I'm In Love" the tactic used is to hold the promotion every Friday. By holding this promo, which is to offer added value to consumers, as a stimulus to maximize sales. One of which is undertaken by Barli, namely by collaborating with several companies or brands. The obstacles are the lack of a graphic design team to focus on work on social media content and operating hours which have the effect of reducing the entry of Barli and this Health Protocol affecting places that are not allowed to be occupied due to regulations from the Government. The reason for using Instagram is because it can attract consumers widely, follow trends, and get positive feedback.
\end{abstract}

Keywords: Covid-19 Pandemic, Coffe Shop, MPR.

Abstrak. Barli Coffee salah satu Coffee Shop di kota Bandung yang berdampingan dengan Museum art ini memiliki konsep yang berbeda dengan konsep-konsep Coffee Shop lainnya. Memasuki era globalisasi, persaingan di berbagai bidang semakin nyata saja. Keberhasilan kinerja Public Relations sebagai item penting organisasi atau perusahaan yang bertugas menciptakan dan mempertahankan nilai atau image positif organisasi semakin tinggi. Jika dilihat dari bauran pemasaran yang dilakukan Barli Coffee ada beberapa bauran pemasaran yang diaplikasikan pada proses strategi marketing di Barli Coffee yaitu Strategi marketing awal, yang dilakukan di bulan pertama oleh Barli yaitu melakukan live music. Strategi marketing kedua, yang Barli Coffee Shop lakukan adalah mengusung konsep "Friday I'm In Love" konsep ini bermaksud mengadakan promo di setiap hari Jum'at. Promo "Friday I'm In Love" didirikan semenjak PSBB diperketat dan konsep dari promo tersebut yaitu setiap konsumen yang datang dapat membayar se-Ikhlasnya. Strategi marketing ketiga yang dilakukan kegiatan yang dapat dilakukan di Barli Coffee yaitu seperti Podcast, dan live concert. Peneliti ingin mengetahui lebih lanjut strategi komunikasi marketing public relations Barli Coffee mengenai promosi "Friday I'm In Love". Tujuannya untuk mengetahui proses strategi komunikasi marketing public relations, hambatanhambatan yang terjadi selama proses strategi komunikasi marketing public relations itu terjadi, dan alasannya kenapa memilih media sosial sebagai media promosi. Metodologi penelitiannya yaitu metode kualitatifdeskriptif dengan pendekatan penelitian studi kasus tunggal holistic. Teknik pengumpulan data yang dilakukan dengan wawancara, observasi, dokumentasi, dan studi pustaka. Subjek penelitian pada key informant terdiri bagian internal yaitu sales \& marketing, dan barista Barli Coffe serta informan pendukungnya yaitu owner Barli Coffee. Hasil penelitiannya yaitu penerapan taktik untuk mempromosikan "Friday I'm In Love" dengan mengadakan promosinya pada setiap hari Jum'at. Dengan diadakan promo ini yaitu menawarkan nilai tambah kepada konsumen, sebagai suatu stimulus untuk mendorong penjualan dengan maksimal. Kemudian salah satu yang dijalani oleh Barli yitu dengan berkolaborasi dengan beberapa perusahaan atau brand. Hambatannya yaitu kurangnya tim design grafis untuk fokus kerja di konten media sosial dan jam operasional yang dampaknya mengurangi pemasukkan Barli dan Protokol Kesehatan ini mempengaruhi tempat-tempat yang tidak boleh ditempati karena adanya aturan dari Pemerintah. Alasan menggunakan media sosial Instagram karena dapat menarik konsumen secara luas, mengikuti trend, dan mendapatkan feedback positif.

Kata Kunci: Pandemi Covid-19, Coffe Shop, MPR 


\section{A. Pendahuluan}

Pada awal dimulainya Barli cafe dan sudah berjalan tiga tahun dengan perkembangan yang bisa dikatakan kurang baik, dikarenakan kurangnya pengelolaan strategi marketing dari pihak manajemen. Sampai pada akhirnya di tahun 2019, Barli pun melakukan pergantian kepemilikan dan merombak kepengurusan manajemen sebelumnya. Pada bulan agustus 2019, Barli Café mempunyai manajamen baru tujuannya dengan mengganti total manajemen baru ini yaitu untuk merubah konsep dan strategi marketing yang akan dijalani oleh Barli sebagai usaha baru dalam menarik konsumen. Selagi merencanakan strategi marketing ini diselangi pula rebranding mengenai Barli café sampai pada penetapan nama menjadi Barli Coffee.

Pada dasarnya public relations mengisi semua lini komunikasi yang terjadi di semua organisasi, baik komersil maupun non komersil. Tak terkecuali dalam berbagai aspek di dunia pemasaran yang pada dasarnya juga memerlukan komunikasi dan hubungan antar pribadi, seperti antara perusahaan dengan target khalayak dari produknya, dengan konsumen dan dengan pelanggan.

Jika dilihat dari fenomena yang terjadi sekarang, dengan adanya pandemi covid-19 ini mempengaruhi perekonomian seluruh masyarakat seperti mempengaruhi perusahaan, usaha makro maupun mikro yang dijalani demi memenuhi kebutuhan diri sendiri dan juga keluarga. Hal ini juga terpikirkan oleh Barli mengenai perekonomiannya pada coffee shop ini, pihaknya memikirkan bagaimana cara untuk tetap dapat menghidupi karyawan-karyawannya akan tetapi tidak merugikan pula konsumennya. Maka pihak Barli pun mulai merancangan strategi agar coffee shop ini tetap berjalan dan tidak merugikan pihak manapun. Alhasil, pihak Barli meluncurkan sebuah promosi "Friday I'm In Love" selama pandemi covid-19. Tujuannya mengadakan promosi ini agar konsumen yang tidak perlu merogoh uang banyak untuk membeli kopi, karena promosi ini konsepnya membeli kopi dengan bayar se-Ikhlasnya.

Oleh karena itu kegiatan yang dilakukan oleh Barli Coffee dalam menjalankan promosinya untuk menarik perhatian konsumen seperti mengadakan pembayaran kopi dengan se-ikhlasnya dan melakukan take away atau menggunakan aplikasi delivery dalam penjualan selama covid-19 dan tetap menjalankan protokol kesehatannya.

Dalam latar belakang penelitian kali ini, setelah dilihat pada pembahasannya mengenai Barli Coffee yang melakukan strategi marketing public relations dengan beberapa bauran promosi yang dilakukannya serta menggunakan komunikasi sebagai kunci dalam menjalankan semua prosesnya. Maka peneliti tertarik untuk meneliti lebih lanjut mengenai strategi komunikasi marketing PR Barli Coffee dalam promosi Friday I'm In Love di era pandemi untuk menarik konsumen.

\section{B. Metodologi Penelitian}

Penulis menggunakan paradigma penelitiannya yaitu Konstruktivisme untuk mengetahui Strategi Komunikasi Marketing Public Relations mengenai promosi "Friday I'm In Love" dilakukan oleh pihak Barli Coffee pada Era Pandemi Covid-19. Alasannya menggunakan paradigm Konstruktivisme pada penelitian ini karena paradigma Konstrutivisme ini dapat melihat bagaimana realitas sosial dari Strategi Komunikasi Marketing Public Relations yang dilakukan oleh pihak Barli Coffee dalam meningkatkan konsumen di masa Pandemi Covid-19 yang sangat mempengaruhi ekonomi di industry kuliner, dapat dipahami sebagai suatu realitas yang dikonstruksikan dan bagaimana konstruksi tersebut terbentuk.

Pada penelitian ini penulis menggunakan penelitian kualitatif dimana penelitian kualitatif sebagai metode ilmiah sering digunakan dan dilaksanakan oleh sekelompok penulis dalam bidang ilmu sosial. Penelitian kulitatif dilaksanakan guna membangun pengetahuan melalui pemahaman dan penemuan. Menurut (Moleong, 2012, p. 6).

Jenis studi kasus yang digunakan dalam penelitian ini adalah jenis tunggal holistik. Penelitian studi kasus tunggal holistic (holistic single-case) adalah penelitian yang menempatkan sebuah kasus sebagai fokus dari penelitian serta ingin mengetahui secara eksplanasi lebih dalam mengenai pola marketing PR dalam merencanakan hingga menjalankan proses strategi marketingnya untuk membangun perekonomian melalui mengadakan promosi "Friday I'm In Love" selama pandemi covid-19. Hal lainnya adalah mencari tahu mengenai hambatan yang terjadi selama menjalankan promosi tersebug, dan mengetahui alasannya 
mengapa media sosial merupakan media utama sebagai alat untuk mempromosikan "Friday I'm In Love".

Peneliti memilih subjek penelitian ini sebagai informan yaitu orang yang memberi informasi mengenai data dan kejadian yang diinginkan. Peneliti memilih subjek peneliti yang merupakan pihak dari Barli Coffee itu sendiri, yaitu:

1. Wahyu Ramadhan Selaku Sales Marketing

2. Rully Selaku Head Barista Barli Coffee

Teknik pengumpulan data dalam penelitian kualitatif ini terdiri dari, wawancara, observasi atau pengamatan lapangan (field observation), dokumentasi, dan studi pustaka.

Dan teknik analisis datanya menggunakan reduksi data, penyajian data, penarikan kesimpulan/verifikasi serta uji keabsahan data menggunakan triangulasi sumber yaitu owner dari Barli Coffee

\section{Hasil dan Pembahasan}

Pola Marketing PR dalam mempromosikan “Friday I'm In Love” di Era Pandemi Covid-19

Awal mula Barli Coffee memulai untuk menjalankan promosi ini yaitu memulai dengan survey yang dilakukan Wahyu, karena kebetulan lingkungannya juga merupakan pengusaha coffee shop dan melakukan sharing mengenai promosi apa yang sekiranya cocok bagi coffee shop yang baru buka, akan tetapi bagi Barli Coffe Shop ini belum melakukan opening karena masih ada konsep yang belum terjalani yaitu merenovasi bangunan Barli. Maka, sambil menunggu waktu dan menyiapkan untuk persiapan renovasi, Barli memulai berjualan dengan konsep asli yang sudah dibangun oleh pihak Museum Art.

Barli memutuskan untuk melakukan strategi yang digunakan yaitu dengan periklanan. Barli melakukan periklanan produk-produknya melalui media sosial Instagram Ads. Sistem Instagram Ads ini akan iklan di snapgram orang-orang dan nantinya orang dapat visit profile Barli untuk melihat promo-promo lainnya atau kontennya.

Pull Strategy Barli Coffee dalam menerapkan taktik untuk mempromosikan "Friday I'm In Love" taktik yang digunakan yaitu dengan mengadakan promosinya pada setiap hari Jum'at, karena biasanya pada hari Jum'at itu ramai oleh anak-anak muda terlebih lagi ramai didatangi pada malam hari seperti misalkan konsumen yang habis pulang kerja mendatangi Barli di hari Jum'at dikarenakan di hari sabtunya libur maka orang-orang akan lebih santai untuk menikmati perbincangan bersama teman-temannya. Sedangkan kalau untuk sabtu-minggu biasanya ramai oleh konsumen yang sudah berkeluarga, ataupun komunitas. Jika konsumen yang datangnya keluarga atau komunitas biasanya tidak menggunakan promosi "Friday I'm In Love". Maka, Wahyu menetapkan untuk mengadakan promosi di setiap hari Jum'at dimana anak-anak muda akan lebih dominan datangnya.

Push Strategy yang digunakan oleh Barli ini dengan diadakan promo ini yaitu menawarkan nilai tambah kepada konsumen, sebagai suatu stimulus untuk mendorong penjualan dengan maksimal. Stimulus ini bertujuan untuk mempengaruhi sikap konsumen untuk membeli produk kopi Barli Coffee dan menjadi konsumen yang loyal terhadap Barli.

Pass Strategy Salah satu yang dijalani oleh Barli yitu dengan berkolaborasi dengan beberapa perusahaan atau brand. Seperti yang dilakukan oleh Barli dengan berkolaborasi dengan provider kartu Tri mengadakan konser daring yang diisi oleh Juicy Luicy, Indah Kus, dan beberapa bintang tamu lainnya. Pihak Barli menyediakan tempat, makanan, dan minuman sedangkan untuk acaranya dipegang oleh perusahaan provider katu Tri. Sebagai Support yang telah menyediakan tempat tentu ini menjadi nilai plus, secara tidak langsung pihak perusahaan akan mempromosikan Barli dan target konsumen Barli pun akan menjadi luas. Acara yang dilakukan secara online ini banyak antusias dari masyarakat dan banyak yang menonton meskipun online. Hal ini memiliki pengaruh dalam memberikan kesan pada konsumen yang menonton dan memberikan pengalaman yang menyenangkan. 
Hambatan yang dihadapi Barli Coffee saat menjalankan promosi di Era Pandemi Covid-19

Kendala dalam pembuatan konten untuk kepenuhan media sosial dalam promosi, seperti yang dijelaskan oleh Suparno (2011:15) dalam Tujuan Marketing PR yaitu:

"Introduksi produk baru." (Suparno, 2011:15).

Kendala yang yang terjadi selama menjalankan promosi adalah yaitu pada internalnya itu sendiri masih kekurangan karyawan, salah satunya kurangnnnya content creator/digital marketing untuk mendesign dan mengkonsep konten-konten untuk di media sosial sehingga masih oleh Wahyu sebagai Sales Marketing yang harus turun tangan. Selain itu, kurangnya interest konsumen jika dilihat dari visit profile Instagram. Maksudnya, dengan menggunakan Instargam Ads terkadang tidak ada yang sesuai dengan goals, yang visit profilenya hanya $20 \%$.

Selain adanya keterbatasan interaksi dengan konsumen adanya ketentuan jam operasional. Hal ini juga mempengaruhi ke pemasukkan Barli karena akan adanya penurunan karena terbatasnya jam operasional. Lalu, keterbatasan interaksi, dikarenakan harus berjaga jarak maka tempat duduk di Barli harus diselang-seling sehingga tidak boleh berhadapan atau berdekatan, ini juga mempengaruhi ke kuantitas konsumen menjadi sedikit karena penggunaan ruangan tidak boleh terlalu berkerumun.

\section{Alasan memilih Instagram sebagai Media dalam menyampaikan promosi}

Instagram $A d s$ ini merupakan fitur Instagram yang dimana memberikan kesempatan bagi para pembisnis untuk mengiklankan produk/usahanya di Instagram. Promosi yang diselenggarakan melalui media sosial Instagram ini terbilang cukup mengenai impact yang didapat dari media sosial tersebut. Dikarenakan pemanfaatan fitur yang tersedia dari media sosial Instagram, seperti Instagram $A d s$ dapat menentukan target yaitu lokasi, dan goals-nya untuk mencapai khalayak sesuai dengan yang diinginkan.

Hal ini salah satu dari bauran promosi yaitu periklanan, seperti yang dijelaskan oleh (Kasmir, 2005, p. 17) mengenai periklanan dalam bauran promosi:

"Iklan merupakan sarana promosi yang sering digunakan oleh perusahaan untuk menginformasikan, menarik, dan memengaruhi calon konsumennya." (Kasmir, 2005:17).

Tentu, promosi pasti digunakan semua perusahaan karena hal ini yang dapat menarik perhatian konsumen ditambah lagi jika masyarakat Indonesia sangat menyukai promosi seperti diskon, buy 1 get 2, dan sebagainya. Hal ini berlaku bagi Barli, Akan tetapi Barli melakukan promo dengan membayar selkhlasnya dalam menu kopi yang sudah ditentukan. Dalam melakukan periklanan ini pun dapat dilakukan berbagai media, dan Barli menggunakan media sosial.

Maka dengan adanya promosi “Friday I'm In Love” merupakan bentuk dari adanya kegiatan marketing PR dalam Barli Coffee, selain itu strategi promosi melalui media sosial ini merupakan salah satu cara untuk bertahan dimasa pandemi covid-19 dan ditengah persaingan antar Coffee shop. Dengan media sosial pula, khalayaknya lebih luas sehingga penerima informasi mengenai apapun akan mudah didapati dan akan menarik perhatian konsumen lebih banyak lagi.

\section{Kesimpulan}

Pola Marketing Public Relations dalam mempromosikan "Friday I'm In Love" di Era Pandemi Covid-19 menggunakan teori three ways yaitu pull strategy, push strategy, pass strategy. Pada pull strategy menerapkan taktik untuk mempromosikan "Friday I'm In Love" taktik yang digunakan yaitu dengan mengadakan promosinya pada setiap hari Jum'at, karena biasanya pada hari Jum'at itu ramai oleh anak-anak muda terlebih lagi ramai didatangi pada malam hari seperti misalkan konsumen yang habis pulang kerja mendatangi Barli di hari Jum'at dikarenakan di hari sabtunya libur maka orang-orang akan lebih santai untuk menikmati perbincangan bersama teman-temannya. Push Strategy Dengan diadakan promo ini yaitu menawarkan nilai tambah kepada konsumen, sebagai suatu stimulus untuk mendorong penjualan dengan maksimal. Stimulus ini bertujuan untuk mempengaruhi sikap konsumen untuk membeli produk kopi Barli Coffee dan menjadi konsumen yang loyal terhadap Barli. Dan pass strategy Salah satu yang dijalani oleh Barli yitu dengan berkolaborasi dengan beberapa perusahaan atau brand. Seperti yang dilakukan oleh Barli dengan berkolaborasi dengan provider kartu Tri mengadakan konser 
daring yang diisi oleh Juicy Luicy, Indah Kus, dan beberapa bintang tamu lainnya.

Hambatan yang dihadapi Barli Coffee saat menjalankan promosi di Era Pandemi Covid19 yaitu adanya kendala pada internal dikarenakan kurangnya karyawan di bagian design grafis yang dimana pada bagian tersebut untuk mengkonsep dan mendesign konten untuk keperluan media sosial dalam mempromosikan promo Barli Coffee dan kendala lainnya yaitu terbatasnya jam operasional sehingga mempengaruhi kepemasukkan Barli Coffee itu sendiri.

Alasan memilih Instagram sebagai media dalam menyampaikan promosi karena dapat menarik perhatian konsumen lebih luas (banyak), mendapatkan feedback positif dari media sosial hasil ini faktor dari Instagram Ads yang menjangkau konsumen lebih luas, dan tentunya mengikuti trend karena jaman sekarang media sosial sudah menjadi media yang banyak diminati masyarakat.

\section{Acknowledge}

Puji serta syukur penulis panjatkan kehadirat Allah SWT yang telah melimpahkan rahmat dan hidayah-Nya sehingga penulis dapat menyelesaikan skripsi yang berjudul "Strategi Komunikasi Marketing PR Barli Coffee” dengan subjudul Studi Kasus Promosi Friday I'm In Love Di Era Pandemi Covid-19.

Penulis berupaya semaksimal mungkin dalam menyelesaikan skripsi ini dan penulis menyadari juga masih banyak kekurang dan jauh dari kata sempurna. Maka dengan segala kerendahan hati, penulis mengharapkan kritik serta saran yang membangun kepada semua pihak guna penyempurna skripsi ini.

Dalam proses penyusunan skripsi ini penulis menyadari bahwa tanpa adanya bimbingan serta bantuan secara moril dan materil dari semua pihak penyusunan skripsi ini tidak akan terwujud. Oleh karena itu, penulis mengucapkan rasa terimakasih kepada.

1. Ibu dan Ayah selaku orang tua yang selalu memberikan do'a tiada henti dan juga selalu memberikan motivasi kepada penulis.

2. Bapak Dr. Septiawan Santana Kurnia, Drs., M.Si. Selaku Dekan Fakultas Ilmu Komunikasi Universitas Islam Bandung yang telah menyetujui dan memberikan kesempatan kepeada peneliti untuk menyusun laporan tugas akhir skripsi ini.

3. Bapak Dr. Maman Suherman, Drs., M.Si. selaku Ketua Bidang Kajian Public Relations Fakultas Ilmu Komunikasi Universitas Islam Bandung yang juga telah memberikan arahan serta menyetujui untuk menyusun laporan tugas akhir skripsi ini.

4. Bapak Dadi Ahmadi, S.Sos., M.I.Kom. selaku dosen pembimbing yang sangat luar biasa membantu peneliti dalam proses penyusunan skripsi ini dari awal hingga akhir dalam memberikan bimbimbingan serta motivasi terhadap peneliti.

5. Kepada seluruh dosen dan staff akademik Fakultas Ilmu Komunikasi Universitas Islam Bandung yang telah memberikan ilmunya dan membantu peneliti dalam mengurus segala urusan mengenai akademik.

6. Kepada Marthalia Fajri Sidharta selaku the best partner yang selalu mendukung peneliti dalam segala keadaan.

7. Kepada sahabat dari awal perkuliahan Edo,Bacil, Rangga, Tegar, Seno, Apra, Fikri Zaka yang senantiasa menemani dari semester awal sampai akhir.

8. Kepada teman - teman kuliah Ilham f, Reza, Burhan, Akmal, Gifa, Bima, Lina, bibeh, Vicky, aiman, ziyan yang sering bercanda dan memberikan dukungan secara tidak langsung dengan cara mereka.

Akhir kata peneliti beharap semoga Allah SWT melimpahkan segala karunia, rahmat serta ridho-Nya atas bantuan yang telah diberikan kepada peneliti. Dengan segala kerendahan hati, semoga skripsi ini berguna dan bermanfaat bagi seluruh pihak. 


\section{Daftar Pustaka}

[1] Afrizal. (2016). Metode Penelitian Kualtitatif: Sebuah Upaya Mendukung Penggunaan Penelitian Kualitatif dalam Berbagai Disiplin Ilmu. Jakarta: PT. Raja Grafindo Persada.

[2] Creswell, J. (2015). Penelitian Kualitatif dan Riset. Yogyakarta: Pustaka Belajar.

[3] Kasmir. (2005). Pemasaran Jasa. Jakarta: Graya Grafindo Persada.

[4] Kriyantono, R. (2006). Teknik Praktis Riset Komunikasi. Jakarta: PT. Kencana Perdana.

[5] Moleong, L. (2012). Metodologi Penelitian Kualitatif. Bandung: Remaja Rosdakarya.

[6] Nasution, C. (2019). Strategi Marketing Public Relations PT. DUA SYNERGY COMMUNICATIONS Dalam Meningkatkan Jumlah Penggunaan Jasa Event Organizer. Jurnal Komunikatif, ix.

[7] Rakhmat, J., Ibrahim, \& Subandi, I. (2017). Metode Penelitian Komunikasi. Edisi Revisi kedua. Bandung: Simbiosa Rekatama Media.

[8] Sugiyono. (2016). Metode Penelitian Kuantitatif, Kualitatif, dan Kombinasi. Bandung: Alfabeta.

[9] Sugiyono. (2017). Metode Penelitian Kuantitaif, Kualitatif, dan R\&D. Bandung: Alfabeta.

[10] Suparmo, L. (2011). Aspek Ilmu Komunikasi. Jakarta: PT. Indeks.

[11] Yin, R. K. (2002). Studi Kasus Desain dan Metode. Penerjemah: M. Djauzi Mudzakir. Jakarta: Raja Grafindo Persada.

[12] Yusuf, A. (2014). Metode Penelitian: Kuantitatif, Kualitatif, \& Penelitian Gabungan. Jakarta: Prenadamedia Group. 